\title{
The effect of compaction of the arable layer in sandy soils on the growth of maize for silage. 1. Critical matric water potentials in relation to soil aeration and mechanical impedance
}

F. R. Boone ${ }^{1}$, H. M. G. van der Werf', B. Kroesbergen ${ }^{1}$, B. A. ten $\operatorname{Hag}^{2}$ and A. Boers $^{1}$

${ }^{1}$ Soil Tillage Laboratory, Agricultural University, Diedenweg 20, 6703 GW Wageningen, Netherlands

${ }^{2}$ Research Station for Arable Farming and Field Production of Vegetables (PAGV), P.O. Box 430, 8200 AK Lelystad, Netherlands

Received 11 July 1985; accepted 13 November 1985

Key words: soil compaction, maize, soil aeration, mechanical impedance

\begin{abstract}
A new approach in defining the range of soil structure which guarantees optimal maize production is proposed. The effect of different degrees of compaction of ploughed sandy soils on soil aeration and mechanical impedance, root growth and subsequent shoot growth of maize was tested in 5 model field experiments. In this first paper the potential effects on soil aeration and penetration resistance are described. The narrower the range of matric water potentials which allow an unimpeded root growth, the greater the potential risks for plant growth and the greater the need for a controlled supply of water. Soil structures which substantially impede root growth even at the most favourable matric water potential are to be classified as dangerous.
\end{abstract}

\section{Introduction}

In the Netherlands on sandy soils liquid livestock manure is spread during winter and early spring on arable land as well as on grassland. To extend this period, soil tillage in early spring is postponed as long as possible. Ploughing is performed late and sowing of maize follows as soon as possible, sometimes even on the same day. Because the loose soil is not settled sufficiently for proper sowing with a precision drill the soil is compacted artificially to some degree at or directly after ploughing. However, plant establishment and growth sometimes are below expectations. In order to gain knowledge about the range of soil structure which guarantees optimal maize production, the effect of different degrees of compaction of ploughed soil on 
soil physical aspects, root and subsequent maize growth was tested in 5 model field experiments. In this article potential effects on soil aeration and penetration resistance are described. A new approach towards critical matrix water potentials in relation to both soil physical growth factors is proposed.

\section{Materials and methods}

\section{Soils}

The experimental fields are located in the eastern part of the Netherlands. Both experiments in Heino (1980 and 1982) are on fine sand, those in Heeten (1981) on loamy fine sand and in Wijhe (1982) on fine sandy loam (de Bakker \& Schelling, 1966) (Table 1). The soil in Heino (1982) had been grassland (ley) for three years. Watertable depth at compaction and sowing was $1.2 \mathrm{~m}$, except for Heeten (1981): $1.7 \mathrm{~m}$ in Heeten $\mathrm{H}$ and $1.45 \mathrm{~m}$ in Heeten $\mathrm{L}$.

\section{Treatments}

Liquid livestock manure (in 1980: 80 or $230 \mathrm{t} \mathrm{ha}^{-1}$, in 1981 and Heino 1982: $80 \mathrm{t} \mathrm{ha}^{-1}$ and in Wijhe 1982: $20 \mathrm{t} \mathrm{ha}^{-1}$ ) was applied during winter and/or early spring. On 1 May (in 1982 three days earlier) the soil was ploughed to a depth of approximately $0.25 \mathrm{~m}$. Within three days after ploughing the soil was compacted and the seedbed prepared. The different degrees of compaction of the arable layer were designated as follows:

$\mathrm{L}=$ loose. Not compacted after ploughing. No separate seedbed preparation.

$\mathrm{CL}=$ compacted lightly. Soil compacted with a packer at ploughing $(0.7 \mathrm{~m}$ diameter, open rings $0.15 \mathrm{~m}$ apart). No separate seedbed preparation.

$\mathrm{CM}=$ compacted moderately. Compacted by driving once all over the soil after ploughing with a $44 \mathrm{~kW}$ tractor on double rear wheels (inflation pressure ca. $150 \mathrm{kPa})$. Seedbed preparation with spring-tine cultivator $(0.05 \mathrm{~m})$.

$\mathrm{CS}=$ compacted severely. Compacted by driving three times all over the soil after ploughing with a $44 \mathrm{~kW}$ tractor on single rear wheels (inflation pressure ca. $150 \mathrm{kPa})$. Seedbed preparation with spring-tine cultivator $(0.05 \mathrm{~m})$.

On the same day (in Wijhe 1982 six days later) maize was sown with a precision drill at a depth of $0.05 \mathrm{~m}$ and a row distance of $0.75 \mathrm{~m}$.

Table 1. Soil characteristics of the arable layer $(0-30 \mathrm{~cm})$.

\begin{tabular}{|c|c|c|c|c|c|}
\hline \multirow[t]{2}{*}{ Location } & \multirow{2}{*}{$\begin{array}{l}\text { Organic } \\
\text { matter } \\
(\%, w / w)\end{array}$} & \multirow{2}{*}{$\begin{array}{l}\mathrm{pH} \\
(\mathrm{KCl})\end{array}$} & \multicolumn{3}{|c|}{ Particle size distribution ( $\%$ mineral fraction) } \\
\hline & & & $<2 \mu \mathrm{m}$ & $2-50 \mu \mathrm{m}$ & $50-2000 \mu \mathrm{m}$ \\
\hline Heino $(1980)$ & 3.3 & 4.9 & 2.7 & 4.2 & 93.1 \\
\hline Heeten-H (1981) & 4.5 & . & 3.3 & 29.2 & 67.5 \\
\hline Heeten-L (1981) & 3.3 & 6.8 & 3.1 & 27.5 & 69.4 \\
\hline Heino (1982) & 4.7 & 5.7 & 3.0 & 5.6 & 91.4 \\
\hline Wijhe (1982) & 3.2 & 4.1 & 10.1 & 13.9 & 76.0 \\
\hline
\end{tabular}




\section{Methods}

Rainfall was measured on the site. Water table depths were measured in tubes. Moisture retentivity curves and volume fractions of pores were determined by applying standard techniques to 10 undisturbed core samples of $100 \mathrm{~cm}^{3}$ from relevant soil layers. Soil matric water potentials $\left(h_{\mathrm{m}}\right)$ were measured with tensiometers and a pressure transducer in duplicate in the ploughed layer $(0.15 \mathrm{~m})$, at ploughpan depth $(0.35 \mathrm{~m})$ and in the subsoil $(0.6 \mathrm{~m})$. Gravimetric soil water contents of composite mixed samples were determined at the same time in all treatments at $0.1 \mathrm{~m}$ depth intervals.

Oxygen diffusion coefficients were determined at $h_{\mathrm{m}}=-0.3$ or $-0.5 \mathrm{~m}(\mathrm{pF}=1.5$ or 1.7$)$ and at $h_{\mathrm{m}}=-1 \mathrm{~m}(\mathrm{pF}=2)$ in 8 undisturbed core samples of $230 \mathrm{~cm}^{3}$ from the arable layer at a depth of $0.1-0.15 \mathrm{~m}$ by a modification of the procedure used by Bakker and Hidding (Boone et al., 1976). Air permeability was measured in the same undisturbed core samples and at the same matric water potentials according to a method proposed by Kmoch (1961) with a hydraulic head of $0.04 \mathrm{~m}$ water. Oxygen concentrations of soil air were determined polarographically in five diffusion chambers $\left(1 \mathrm{~cm}^{3}\right)$ placed at the same depths as the tensiometers.

Penetration resistances were measured (10 replicates) with a recording penetrometer (van Soesbergen \& Vos, 1971) during the growing season at various soil water contents. A cone base of $1 \mathrm{~cm}^{2}$ with a $60^{\circ}$ angle was used.

Root diameters of main root axes and first-order laterals $(n=50)$ were measured with a microscope at small magnification (July 1982).

\section{Results}

\section{The volume fraction of pores and gas}

Porosity of the arable layer decreases slightly when the ploughed soil (treatment L) is compacted with a packer (treatment CL), clearly when a tractor on double rear wheels is used (treatment CM) and strongly when this tractor on single rear wheels drives 3 times on the surface (treatment CS). Because the same equipment and procedure was used, compaction effects in the various experiments can be compared and related to soil stability and water content. Porosities in treatments L and CL are larger on the fine sand previously in grass and in the fine sandy loam than in the other experiments (Fig. 1). Soil water content at compaction depends on the actual matric water potential and the water retentivity curve of that particular soil. Gravimetric soil water content at field capacity $\left(h_{\mathrm{m}} \approx-0.8 \mathrm{~m}=\mathrm{pF}=1.9\right)$ is highest in the loamy fine sand and lowest in the fine sand. The actual matric water potential at compaction depends on rainfall in the previous period, the depth of the water table and the water conductivity-matric water potential relationship. It appears (Table 2) that the smallest porosity in treatment CS is found on the loamy fine sand in the lower part $\mathrm{L}$ of the experiment and is associated with the highest water content. The largest porosity is found on the fine sand previously in grass and associated with the smallest water content.

In treatment CS the volume fraction of gas at a high matric water potential $\left(h_{\mathrm{m}}=\right.$ $-0.5 \mathrm{~m}$ ) is small, especially in the loamy fine sand with values close to 0.05 (Table 
F. R. BOONE ET AL.

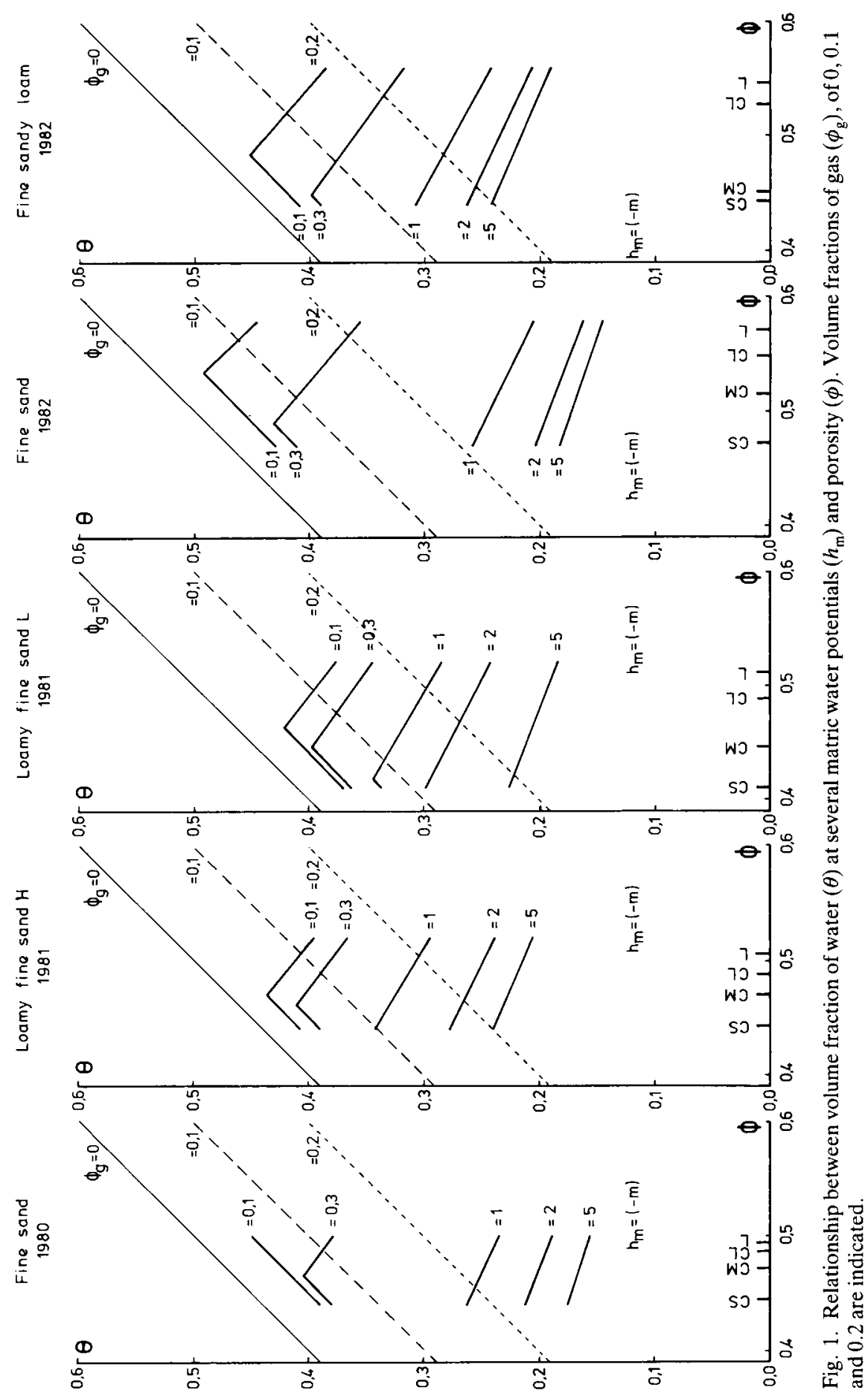


Table 2. Matric water potential $h_{\mathrm{m}}(\mathrm{m})$ and gravimetric water content $w\left(\mathrm{~kg} \mathrm{~kg}^{-1}\right)$ at compaction and volume fraction of pores $\phi\left(\mathrm{m}^{3} \mathrm{~m}^{-3}\right)$ and volume fraction of gas $\phi_{\mathrm{g}}\left(\mathrm{m}^{3} \mathrm{~m}^{-3}\right)$ at $h_{\mathrm{m}}=-0.5$ and $h_{\mathrm{m}}=-1 \mathrm{~m}$ after severe compaction (treatment $\mathrm{CS}$ ).

\begin{tabular}{|c|c|c|c|c|c|c|}
\hline \multirow[t]{3}{*}{ Soil } & \multirow[t]{3}{*}{ Year } & \multicolumn{2}{|c|}{ At compaction } & \multicolumn{3}{|c|}{ After compaction } \\
\hline & & \multirow[t]{2}{*}{$-h_{\mathrm{m}}$} & \multirow[t]{2}{*}{$w$} & \multirow[t]{2}{*}{$\phi$} & \multicolumn{2}{|l|}{$\phi_{\mathrm{g}}$} \\
\hline & & & & & $-h_{\mathrm{m}}=0.5$ & $-h_{\mathrm{m}}=1$ \\
\hline Fine sand & 1980 & 0.8 & 0.21 & 0.445 & 0.088 & 0.152 \\
\hline Loamy fine sand $(\mathbf{H})$ & 1981 & 1.0 & 0.21 & 0.443 & 0.055 & 0.080 \\
\hline Loamy fine sand (L) & 1981 & 0.9 & 0.22 & 0.411 & 0.057 & 0.071 \\
\hline Fine sand & 1982 & 0.9 & 0.20 & 0.472 & 0.089 & 0.188 \\
\hline Fine sandy loam & 1982 & 0.9 & 0.21 & 0.443 & 0.092 & 0.131 \\
\hline
\end{tabular}

2). When the soil matric potential decreases from $h_{\mathrm{m}}=-0.5$ to $h_{\mathrm{m}}=-1 \mathrm{~m}$ the volume fraction of gas doubles in the fine sand, clearly increases in the fine sandy loam but increases only slightly in the loamy fine sand. The volume fraction of gas is higher when the soil is compacted moderately. At $h_{\mathrm{m}}=-1 \mathrm{~m}$ the difference in volume fraction of gas between treatments CM and CS is 1.5-1.7 times the difference in porosity and is small in the fine sandy loam and large in the fine sand previously in grass.

\section{Soil aeration}

Transport of oxygen from the soil surface to deeper soil layers is determined by diffusion. The diffusion coefficient of oxygen in soils, $D\left(\mathrm{O}_{2}\right)$, therefore, is an important index. For the experimental fields different relations are found between $D\left(\mathrm{O}_{2}\right)$ and the volume fraction of gas $\phi_{\mathrm{g}}$ (Fig. 2). In these relations two aspects are to be distinguished: the volume fraction of blocked gas $\phi_{\mathrm{gb}}$ at which $D\left(\mathrm{O}_{2}\right)$ approaches zero and the relation between $D\left(\mathrm{O}_{2}\right)$ and $\phi_{\mathrm{g}}$ at a higher air fraction. $\phi_{\mathrm{gb}}$ is 0.08 in the fine sand of 1980 and 0.05 in all other cases. At small gas fractions, $D\left(\mathrm{O}_{2}\right)$ is higher in the fine sandy loam and the fine sand previously in grass than in the fine sand of 1980. The loamy fine sand has an intermediate position. At higher gas fractions the relationships converge.

The figures available do not show a distinct influence of $\phi$ on the $D\left(\mathrm{O}_{2}\right)-\phi_{\mathrm{g}}$ relation. The most important effect of compaction on $D\left(\mathrm{O}_{2}\right)$, therefore, is the effect on the gas fraction present at a certain matric water potential. By using the appropriate water retentivity curve, the matric water potential at which $D\left(\mathrm{O}_{2}\right)$ reaches a critical value is derived.

When in a $0.3 \mathrm{~m}$ thick soil layer with a very high oxygen consumption $\left(10^{3} \mathrm{mg} \mathrm{O}_{2}\right.$ $\left.\mathrm{m}^{-2} \mathrm{~h}^{-1}=0.93 \mathrm{mg} \mathrm{O}_{2} \mathrm{~m}^{-3} \mathrm{~s}^{-1}\right)$ the oxygen concentration should not decrease below $10 \%, D\left(\mathrm{O}_{2}\right)$ should equal $3 \cdot 10^{-7} \mathrm{~m}^{2} \mathrm{~s}^{-1}$ (Bakker \& Hidding, 1970). This $D\left(\mathrm{O}_{2}\right)$ can be regarded as a safe Upper Critical Aeration Limit (UCAL). Because the diffusion of oxygen in free air at 1 bar and $20^{\circ} \mathrm{C}, D_{0}=0.201$, the relative gas diffusion coefficient $D\left(\mathrm{O}_{2}\right) / D_{0}$ at this UCAL is $15 \cdot 10^{-7} \mathrm{~m}^{2} \mathrm{~s}^{-1}$. When in the same soil layer the oxygen consumption is 10 times lower $\left(10^{2} \mathrm{mg} \mathrm{O}_{2} \mathrm{~m}^{-2} \mathrm{~h}^{-1}=0.093 \mathrm{mg} \mathrm{O}_{2} \mathrm{~m}^{-3} \mathrm{~s}^{-1}\right)$ 


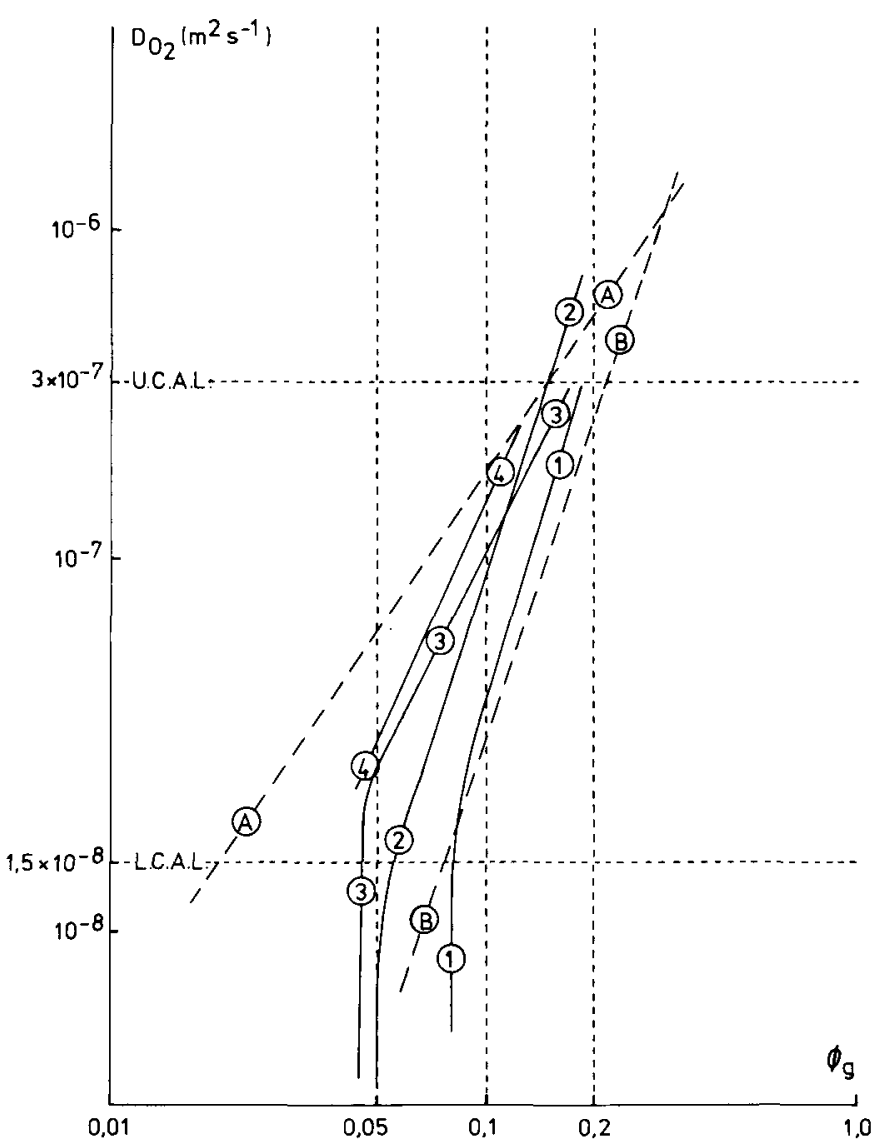

Fig. 2. Relationship between oxygen diffusion coefficient $D\left(\mathrm{O}_{2}\right)$ and volume fraction of gas $\left(\phi_{\mathrm{g}}\right)$. The relationship for a single-grain structure and a very well structured loam soil are added $(1=$ fine sand $(1980) ; 2=$ loamy fine sand (1981); $3=1$ after 3 year grass (1982); 4 = fine sandy loam (1982); $\mathrm{A}=$ very well structured loam $\left(D\left(\mathrm{O}_{2}\right)=0.05 \phi_{\mathrm{g}}{ }^{1.5}\right) ; \mathrm{B}=$ single-grain structure $\left.\left(D\left(\mathrm{O}_{2}\right)=0.3 \phi_{\mathrm{g}}{ }^{3.0}\right)\right)$.

and the oxygen concentration is allowed to decrease to $1 \%$ a 20 times Lower Critical Aeration Limit (LCAL) of $1.5 \cdot 10^{-8} \mathrm{~m}^{2} \mathrm{~s}^{-1}$ is obtained which equals a relative gas diffusion coefficient of $7.5 \cdot 10^{-8} \mathrm{~m}^{2} \mathrm{~s}^{-1}$. In most conditions this value is fully insufficient. For the various experimental fields these criteria of $D\left(\mathrm{O}_{2}\right)$ are translated into critical matric water potentials (Table 3 ). It appears that the matric water potential at the LCAL is generally high: $-0.2 \mathrm{~m}$ in treatment CM and -0.3 in treatment CS. In the loamy fine sand, however, the potential is lower: $-0.3 \mathrm{~m}$ and $-0.6 \mathrm{~m}$ in the higher part $(\mathrm{H})$, respectively $-0.6 \mathrm{~m}$ and $-0.8 \mathrm{~m}$ in the lower part $(\mathrm{L})$ of the field. $\phi_{\mathrm{g}}$ as this limit is always close to $\phi_{\mathrm{gb}}$. The matric water potential at the UCAL is much lower than at the LCAL and clearly different for the various experiments and degrees of compaction. In treatment $\mathrm{CM}$ values are between $-0.6 \mathrm{~m}$ (fine sand previously in grass) and $-2 \mathrm{~m}$ (loamy fine sand $\mathrm{L}$ ). For treatment $\mathrm{CS}$ values are be- 
Table 3. Matric water potential $h_{\mathrm{m}}(\mathrm{m})$ and volume fraction of gas $\phi_{\mathrm{g}}\left(\mathrm{m}^{3} \mathrm{~m}^{-3}\right)$ at which the relative gas diffusion coefficient $D\left(\mathrm{O}_{2}\right) / D_{0}=15 \cdot 10^{-7} \mathrm{~m}^{2} \mathrm{~s}^{-1}$ (UCAL) and $D\left(\mathrm{O}_{2}\right) / D_{0}=7.5 \cdot 10^{-8} \mathrm{~m}^{2} \mathrm{~s}^{-1}$ (LCAL) for the moderately (CM) and severely (CS) compacted treatments.

\begin{tabular}{|c|c|c|c|c|c|c|}
\hline \multirow[t]{2}{*}{ Soil } & \multirow[t]{2}{*}{ Year } & \multirow{2}{*}{$\begin{array}{l}\text { Treat- } \\
\text { ment }\end{array}$} & \multicolumn{2}{|c|}{ LCAL } & \multicolumn{2}{|c|}{ UCAL } \\
\hline & & & $-h_{\mathrm{m}}$ & $\phi_{\mathrm{g}}$ & $-h_{\mathrm{m}}$ & $\phi_{\mathrm{g}}$ \\
\hline \multirow[t]{2}{*}{ Fine sand } & \multirow[t]{2}{*}{1980} & CM & 0.2 & 0.07 & 0.9 & 0.19 \\
\hline & & CS & 0.3 & 0.08 & 1.6 & 0.20 \\
\hline \multirow[t]{2}{*}{ Loamy fine sand $\mathrm{H}$} & \multirow[t]{2}{*}{1981} & $\mathrm{CM}$ & 0.3 & 0.06 & 1.0 & 0.15 \\
\hline & & $\mathrm{CS}$ & 0.6 & 0.07 & 2.0 & 0.16 \\
\hline \multirow[t]{2}{*}{ Loamy fine sand $\mathrm{L}$} & \multirow[t]{2}{*}{1981} & $\mathrm{CM}$ & 0.6 & 0.06 & 2.0 & 0.15 \\
\hline & & CS & 0.8 & 0.07 & 3.0 & 0.16 \\
\hline \multirow[t]{2}{*}{ Fine sand } & \multirow[t]{2}{*}{1982} & $\mathrm{CM}$ & 0.2 & 0.05 & 0.6 & 0.19 \\
\hline & & CS & 0.3 & 0.05 & 0.9 & 0.18 \\
\hline \multirow[t]{2}{*}{ Fine sandy loam } & \multirow[t]{2}{*}{1982} & $\mathrm{CM}$ & 0.2 & 0.05 & 1.0 & 0.15 \\
\hline & & CS & 0.3 & 0.05 & 1.2 & 0.15 \\
\hline
\end{tabular}

tween $-0.9 \mathrm{~m}$ and $-3 \mathrm{~m}$. When the soil is compacted severely and the oxygen consumption is high, matric water potential in the fine sand (1980) and especially in the loamy fine sand should be considerably lower than at field capacity. In all experiments limiting $\phi_{\mathrm{g}}$ is between 0.15 and 0.20 .

Another indication of a potential risk for an insufficient soil aeration due to compaction can be derived from the measurement in a steady state of the volume fraction of oxygen when the soil is at field capacity and the oxygen consumption by the crop is still negligible. It appears that in all experiments the measurements at emergence of the maize crop are appropriate in this respect. At that time there is a marked response in oxygen concentrations (Table 4). Concentrations in treatment CS of - the fine sand previously in grass drop sharply with depth although $D\left(\mathrm{O}_{2}\right)$ is above the UCAL. From the combination of the apparent oxygen diffusion coefficient and the volume fraction of oxygen at a depth of $0.15 \mathrm{~m}$ the oxygen consumption $\alpha$ has been calculated (Table 4 ) assuming that the oxygen consumption is evenly distributed between the surface $(z=0)$ and the lower boundary $(\mathrm{z}=\mathrm{L})$ of a layer with thickness $\mathrm{L}$, and no oxygen is consumed below this layer.

The flux $f\left(\mathrm{O}_{2}\right)$ at depth $\mathrm{z}(0<z<\mathrm{L})$ is:

$$
f\left(\mathrm{O}_{2}\right)=\alpha(\mathrm{L}-z)
$$

and according to the first law of Fick:

$$
f\left(\mathrm{O}_{2}\right)=-D\left(\mathrm{O}_{2)} \mathrm{d} x\left(\mathrm{O}_{2}\right) \mathrm{d} z\right.
$$

$f\left(\mathrm{O}_{2}\right)=$ flux of oxygen $\left(\mathrm{kg} \mathrm{m}^{-2} \mathrm{~s}^{-1}\right)$

$D\left(\mathrm{O}_{2}\right)=$ oxygen diffusion coefficient in soil $\left(\mathrm{m}^{2} \mathrm{~s}^{-1}\right)$

$\chi\left(\mathrm{O}_{2}\right)=$ mass concentration of oxygen in the air phase $\left(\mathrm{kg} \mathrm{m}^{-3}\right)$

$\alpha=$ oxygen consumption $\left(\mathrm{kg} \mathrm{m}^{-3} \mathrm{~s}^{-1}\right)$

$(1)+(2)$ yields: 
Table 4. Volume fraction of gas $\phi_{\mathrm{g}}\left(\mathrm{m}^{3} \mathrm{~m}^{-3}\right)$, oxygen diffusion coefficient $D\left(\mathrm{O}_{2}\right)\left(10^{-7} \mathrm{~m}^{2} \mathrm{~s}^{-1}\right)$, volume fraction of oxygen $\mathrm{O}_{2}\left(\mathrm{~m}^{3} \mathrm{~m}^{-3}\right.$ gas) at $0.15 \mathrm{~m}$ depth, and oxygen consumption $\alpha\left(10^{-1} \mathrm{mg} \mathrm{O}_{2} \mathrm{~m}^{3} \mathrm{~s}^{-1}\right)$ at emergence.

\begin{tabular}{|c|c|c|c|c|c|c|}
\hline Soil & Year & Treatment & $\phi_{\mathrm{g}}$ & $\mathrm{O}_{2}$ & $D\left(\mathrm{O}_{2}\right)$ & $\alpha$ \\
\hline \multirow[t]{3}{*}{ Fine sand } & \multirow[t]{3}{*}{1980} & $\mathrm{CL}$ & 0.208 & 0.198 & 4.3 & 2.2 \\
\hline & & $\mathrm{CM}$ & 0.188 & 0.184 & 3.0 & 3.2 \\
\hline & & CS & 0.146 & 0.144 & 1.5 & 4.1 \\
\hline \multirow[t]{3}{*}{ Loamy fine sand $(\mathrm{H})$} & \multirow{3}{*}{1981} & CL & 0.249 & 0.199 & 8.0 & 3.6 \\
\hline & & $\mathrm{CM}$ & 0.192 & 0.182 & 4.8 & 5.6 \\
\hline & & CS & 0.138 & 0.122 & 2.2 & 7.8 \\
\hline \multirow[t]{3}{*}{ Loamy fine sand (L) } & \multirow[t]{3}{*}{1981} & $\mathrm{CL}$ & 0.236 & 0.197 & 7.0 & 3.8 \\
\hline & & $\mathrm{CM}$ & 0.170 & & 3.6 & \\
\hline & & $\mathrm{CS}$ & 0.141 & 0.130 & 2.4 & 7.8 \\
\hline \multirow[t]{3}{*}{ Fine sand } & \multirow[t]{3}{*}{1982} & $\mathrm{CL}$ & 0.313 & 0.194 & 20.0 & 13.3 \\
\hline & & $\mathrm{CM}$ & 0.261 & 0.168 & 8.0 & 14.0 \\
\hline & & CS & 0.196 & 0.062 & 3.6 & 22.1 \\
\hline \multirow[t]{3}{*}{ Fine sandy loam } & \multirow[t]{3}{*}{1982} & CL & 0.275 & 0.203 & 12.0 & 3.5 \\
\hline & & $\mathrm{CM}$ & 0.181 & 0.184 & 4.5 & 4.9 \\
\hline & & CS & 0.166 & 0.166 & 3.8 & 7.0 \\
\hline
\end{tabular}

$$
\begin{aligned}
\mathrm{d} \chi\left(\mathrm{O}_{2}\right) & =\left[\alpha / D\left(\mathrm{O}_{2}\right)\right](\mathrm{L}-z) \mathrm{d} z \\
& =\left[\alpha / D\left(\mathrm{O}_{2}\right)\right] \int \mathrm{d}\left(\mathrm{L} z-z^{2} / 2\right)
\end{aligned}
$$

When the change in oxygen concentration between the soil surface to depth $z=$ $\Delta \chi\left(\mathrm{O}_{2}\right)$ :

$$
\alpha=-\left[D\left(\mathrm{O}_{2}\right) \cdot \Delta \chi\left(\mathrm{O}_{2}\right)\right] /\left(\mathrm{L} z-z^{2} / 2\right)
$$

In the calculation the arable layer $\mathrm{L}$ is $0.3 \mathrm{~m}$ and $D\left(\mathrm{O}_{2}\right)$ is constant with depth. Because the diffusion coefficient is higher in than beneath the seedbed, it is calculated that $\alpha$ is underestimated by $25 \%$ at maximum. Soil respiration at emergence has been very high in the 1982 experiment on fine sand previously in grass. Although the same amount of liquid livestock manure is applied soil respiration of the loamy fine sand is only one third. The oxygen consumption in the 1980 experiment on fine sand is smallest although 4 times as much manure is applied. This coincided with a lower temperature: mean ambient air temperature at emergence in the second decade of May was 12.7 instead of $14.2{ }^{\circ} \mathrm{C}$. The calculations show also a marked influence of the degree of compaction on the oxygen consumption. Severe compaction nearly doubled the consumption on volume basis. Only $8-18 \%$ of this increase is explained by difference in porosities between treatments CL and CS. 


\section{Mechanical resistance}

The mechanical restriction roots encounter is a function of the dimensions and continuity of the system of macropores, the diameters of individual roots and the energy necessary to widen pore necks and pores smaller than individual roots.

The air permeability and gas diffusion coefficient give information about the dimensions and continuity of the macropores. The flux of oxygen per cross-sectional area with $n$ straight, parallel cylindrical pores of one size perpendicular to the diffusion is:

$$
f\left(\mathrm{O}_{2}\right)=n \pi r^{2} D_{\mathrm{c}}^{\mathrm{d} z\left(\mathrm{O}_{2}\right) / \mathrm{ds}}
$$

with $D_{\mathrm{c}}=$ oxygen diffusion coefficient in a capillary tube $\left(\mathrm{m}^{2} \mathrm{~s}^{-1}\right)$ with radius $r(\mathrm{~m})$. In pores with $r>1.5 \mu \mathrm{m}\left(h_{\mathrm{m}}=-10 \mathrm{~m}\right)$ the friction of the pore walls is negligible compared to the internal friction in the gas. In moist soils we therefore can use the diffusion coefficient of oxygen in free gas $D_{0}$. If the pores are of various sizes and $n_{\mathrm{i}}$ is the number of pores in the $i$ th pore size class with radius $r_{\mathrm{i}}$ divided by the total cross sectional area, than the total flux yields:

$$
f\left(\mathrm{O}_{2}\right)=-\Sigma n_{\mathrm{i}} \pi r_{\mathrm{i}}^{2} D_{0}{ }^{\mathrm{d} x}\left(\mathrm{O}_{2}\right) / \mathrm{d} s
$$

In an isotropical soil the total area of soil pores $\Sigma n_{\mathrm{i}} \pi r_{\mathrm{i}}^{2}$ per unit cross-sectional area equals $\Sigma \Delta\left(\phi_{\mathrm{g}}\right)_{\mathrm{i}}=\phi_{\mathrm{g}}$. Soil pores normally are not parallel and therefore a geometrical reduction factor $\tau(<1)$ is introduced:

$$
f\left(\mathrm{O}_{2}\right)=-\tau \phi_{\mathrm{g}} D_{0}{ }^{\mathrm{d} \chi\left(\mathrm{O}_{2}\right) / \mathrm{d} s}=-D\left(\mathrm{O}_{2}\right)\left[\mathrm{d} \chi\left(\mathrm{O}_{2}\right) / \mathrm{d} s\right]
$$

Mass flow of air per cross-sectional area in a soil with $n$ straight, parallel cylindrical pores with radius $r$ perpendicular to the flow is according to Poiseuilles' law:

$$
f_{\mathrm{a}}=-\left(n \pi r^{4} / 8 \eta\right)(\mathrm{d} p / \mathrm{d} s)
$$

$$
\text { with } \begin{aligned}
f_{\mathrm{a}} & =\text { flux density of air }\left(\mathrm{m}^{3} \mathrm{~m}^{-2} \mathrm{~s}^{-1}=\mathrm{m} \mathrm{s}^{-1}\right) \\
\eta & =\text { viscosity of air }\left(\text { at } 1 \text { bar and } 20{ }^{\circ} \mathrm{C} \approx 20 \mu \mathrm{Pa} \mathrm{s}\right) \\
\mathrm{d} p / \mathrm{d} s & =\text { air pressure gradient }\left(\mathrm{Pa} \mathrm{m}^{-1}\right)
\end{aligned}
$$

If the pores are of various sizes and $n_{\mathrm{i}}$ is the number of pores in the $i$ th pore size class with radius $r_{\mathrm{i}}$ than the flux is:

$$
f_{\mathrm{a}}=1 /(8 \eta) \Sigma n_{\mathrm{i}} \pi r_{\mathrm{i}}^{4}(\mathrm{~d} p / \mathrm{d} s)
$$

In an isotropical soil with non-parallel pores the geometrical reduction factor $\tau$ has to be introduced as was done for diffusion:

$$
f_{\mathrm{a}}=\tau / 8 \eta \phi_{\mathrm{g}} r_{\mathrm{i}}^{2}(\mathrm{~d} p / \mathrm{d} s)=-K_{\mathrm{a}}(\mathrm{d} p / \mathrm{d} s)
$$

with $K_{\mathrm{a}}=$ air conductivity $\left(\mathrm{m}^{2}\right)$. Air conductivity in contrast to gas diffusion (Eq. 7), 
Table 5. Volume fraction of gas $\phi_{\mathrm{g}}$, intrinsic air permeability $K_{\mathrm{ia}}$ and relative gas diffusion coefficient $D\left(\mathrm{O}_{2}\right) / D_{0}$ per volume percent of gas and the ratio $K_{\mathrm{ia}} /\left[D\left(\mathrm{O}_{2}\right) / D_{0}\right]$ of treatment $\mathrm{CS}$ at a matric water potential $h_{\mathrm{m}}=-0.3 \mathrm{~m}$ and the increase between $h_{\mathrm{m}}=-0.3 \mathrm{~m}$ and $h_{\mathrm{m}}=-1 \mathrm{~m}$, respectively.

\begin{tabular}{|c|c|c|c|c|c|c|c|c|c|}
\hline \multirow[t]{2}{*}{ Soil } & \multirow[t]{2}{*}{ Year } & \multicolumn{4}{|c|}{$h_{\mathrm{m}}=-0.3 \mathrm{~m}$} & \multicolumn{4}{|c|}{$\Delta\left(\left(h_{\mathrm{m}}=-1 \mathrm{~m}\right)-\left(h_{\mathrm{m}}=-0.3 \mathrm{~m}\right)\right)$} \\
\hline & & $\begin{array}{l}\phi_{\mathrm{g}} \\
\left(\mathrm{m}^{3} \mathrm{~m}^{-3}\right)\end{array}$ & $\begin{array}{l}\frac{K_{\text {ia }}}{\phi_{\mathrm{g}}} \\
\left(10^{-12} \mathrm{~m}^{2}\right)\end{array}$ & $\begin{array}{l}\frac{D\left(\mathrm{O}_{2}\right)}{\phi_{\mathrm{g}} D_{0}} \\
\left(10^{-7} \mathrm{~m}^{2} \mathrm{~s}^{-1}\right)\end{array}$ & $\begin{array}{l}\frac{K_{\mathrm{ia}} D_{0}}{D\left(\mathrm{O}_{2}\right)} \\
\left(10^{-5} \mathrm{~s}\right)\end{array}$ & $\begin{array}{l}\Delta \phi_{\mathrm{g}} \\
\left(\mathrm{m}^{3} \mathrm{~m}^{-3}\right)\end{array}$ & $\begin{array}{l}\Delta \frac{K_{\mathrm{ia}}}{\phi_{\mathrm{g}}} \\
\left(10^{-12} \mathrm{~m}^{2}\right)\end{array}$ & $\begin{array}{l}\Delta \frac{D\left(\mathrm{O}_{2}\right)}{\phi_{\mathrm{g}} D_{0}} \\
\left(10^{-7} \mathrm{~m}^{2} \mathrm{~s}^{-1}\right)\end{array}$ & $\begin{array}{l}\Delta \frac{K_{\mathrm{ia}} D_{0}}{D\left(\mathrm{O}_{2}\right)} \\
\left(10^{-5} \mathrm{~s}\right)\end{array}$ \\
\hline $\begin{array}{l}\text { Fine sand } \\
\text { Loamy fine }\end{array}$ & $(1980)$ & 0.084 & 6.4 & 8 & 0.8 & 0.066 & 65.0 & 105 & 0.62 \\
\hline sand $(\mathrm{H})$ & $(1981)$ & 0.046 & 0.5 & 2 & 0.25 & 0.033 & 5.8 & 70 & 0.08 \\
\hline $\begin{array}{l}\text { Fine sand } \\
\text { Fine sandy }\end{array}$ & $(1982)$ & 0.044 & 13.0 & 20 & 0.65 & 0.144 & 21.0 & 110 & 0.20 \\
\hline loam & $(1982)$ & 0.043 & 13.0 & 29 & 0.45 & 0.088 & 45.0 & 125 & 0.36 \\
\hline
\end{tabular}

therefore, is strongly dependent on the radii of the largest air-filled pores. Macropores with diameters equal or larger than individual roots are of special interest because they largely determine soil rootability. These pores are created by soil tillage but when a tilled soil is compacted, especially the largest pores disappear (Boone et al., 1985). Soil tillage and soil compaction therefore influence air permeability measured at high matric water potentials more than the gas diffusion coefficient.

In the present experiments $\phi_{\mathrm{g}}$ at $h_{\mathrm{m}}=-0.3 \mathrm{~m}$, at which pores equivalent with a diameter of $\geqslant 100 \mu \mathrm{m}$ are gas-filled, is close to $\phi_{\mathrm{gb}}$. Therefore both the intrinsic air permeability $K_{\text {ia }}=\eta K_{\mathrm{a}}$ and the relative gas diffusion coefficient $D\left(\mathrm{O}_{2}\right) / D_{0}$ is small (Table 5). The fine sand previously in grass and the fine sandy loam compare relatively favourable, the loamy fine sand relatively unfavourable. When $K_{\mathrm{a}}$ and $D\left(\mathrm{O}_{2}\right)$ are determined at the same matric water potential then $\tau$ is identical. The ratio $K_{\mathrm{ia}} D_{0} / D\left(\mathrm{O}_{2}\right)$ then yields information about $\Sigma r_{\mathrm{i}}^{2}$ and at high matric water potentials therefore about the largest pores. It appears at $h_{\mathrm{m}}=-0.3 \mathrm{~m}$ the loamy fine sand has the smallest and the fine sand of 1980 has the largest ratio. Between $h_{\mathrm{m}}=$ -0.3 and $h_{\mathrm{m}}=-1 \mathrm{~m}$, equivalent with pores of $100-30 \mu \mathrm{m}, K_{\mathrm{ia}}$ and $D\left(\mathrm{O}_{2}\right)$ indices increase relatively strongest on both soils with the smallest indices at $h_{\mathrm{m}}=-0.3 \mathrm{~m}$. Especially in these soils part of the ineffective pores become effective and contribute

Table 6. Diameter of main root axes and first-order laterals of maize (sampling depth $10-20 \mathrm{~cm} ; n=50$ ).

\begin{tabular}{lllll}
\hline Treatment & \multicolumn{2}{l}{ Main root axes } & & \multicolumn{2}{l}{ First-order laterals } \\
\cline { 2 - 3 } & $\bar{X}(\mu \mathrm{m})$ & $s_{\mathrm{x}}^{-}(\mu \mathrm{m})$ & $\bar{X}(\mu \mathrm{m})$ & $s_{\mathrm{x}}^{-}(\mu \mathrm{m})$ \\
$\mathrm{L}$ & 1037 & 22 & 314 & 10 \\
$\mathrm{CL}$ & 1607 & 28 & 442 & 16 \\
$\mathrm{CM}$ & 1911 & 38 & 533 & 18 \\
$\mathrm{CS}$ & 2208 & 62 & 640 & 24 \\
\hline
\end{tabular}


to the transport of gas. The ratios again indicate that the pores in the fine sand are relatively large and those in the loamy fine sand are relatively small.

In treatment $\mathrm{L}$ of the fine sand previously in grass, main root axes and first-order laterals of maize have diameters of about 1000 and $300 \mu \mathrm{m}$ respectively (Table 6). The clearly thicker roots in treatment $\mathrm{CL}$ indicate that in this soil pores with a size equal or larger than main root axes are lost easily by compaction. This process proceeds at further compaction.

Penetration resistance at field capacity is small in treatment $\mathrm{L}$, slightly higher in treatment $\mathrm{CM}$ and values are still moderate in treatment CS. A highest value of 1.5 $\mathrm{MPa}$ is found in the loamy fine sand with the smallest porosity (Table 7). Penetration resistance increases when soil water content decreases and distinctly more at small than at a large porosity. Root growth decreases when roots are mechanically impeded. At $3 \mathrm{MPa}$ growth is a fraction of the growth without impedance or completely stops in a homogeneous soil (Taylor \& Gardner, 1963; Boone \& Veen, 1982). This penetration resistance can be regarded as an Upper Critical Mechanical Limit (UCML). As a Lower Critical Mechanical Limit (LCML) the penetration re-

Table 7. Mean cone resistance (MPa) between 0.1 and $0.15 \mathrm{~m}$ depth at field capacity $\left(h_{\mathrm{m}}=-0.8 \mathrm{~m}\right)$.

\begin{tabular}{llllll}
\hline Soil & Year & \multicolumn{2}{l}{ Treatment } & & \\
\cline { 3 - 6 } & & $\mathrm{L}$ & $\mathrm{CL}$ & $\mathrm{CM}$ & $\mathrm{CS}$ \\
Fine sand & & & & & \\
Loamy fine sand (H) & 1980 & 0.6 & 0.5 & 0.7 & 1.1 \\
Loamy fine sand (L) & 1981 & 0.6 & 0.8 & 1.0 & 1.3 \\
Fine sand & 1982 & 0.6 & 0.6 & 1.0 & 1.5 \\
Fine sandy loam & 1982 & 0.6 & 0.6 & 0.8 & 1.1 \\
\hline
\end{tabular}

Table 8. Matric water potential $\left(h_{\mathrm{m}}\right)$ at a cone resistance of 1.5 (LCML) and 3.0 MPa (UCML) and corresponding decrease in volumetric fraction of water $(\Delta \theta)$ between field capacity $\left(h_{\mathrm{m}}=-0.8 \mathrm{~m}\right)$ and this matric water potential, respectively.

\begin{tabular}{|c|c|c|c|c|c|c|}
\hline \multirow[t]{2}{*}{ Soil } & \multirow[t]{2}{*}{ Year } & \multirow{2}{*}{$\begin{array}{l}\text { Treat- } \\
\text { ment }\end{array}$} & \multicolumn{2}{|c|}{ LCML } & \multicolumn{2}{|l|}{ UCML } \\
\hline & & & $\begin{array}{l}-h_{\mathrm{m}} \\
(\mathrm{m})\end{array}$ & $\begin{array}{l}\Delta \theta \\
\left(\mathrm{m}^{3} \mathrm{~m}^{-3}\right)\end{array}$ & $\begin{array}{l}-h_{\mathrm{m}} \\
(\mathrm{m})\end{array}$ & $\begin{array}{l}\Delta \theta \\
\left(\mathrm{m}^{3} \mathrm{~m}^{-3}\right)\end{array}$ \\
\hline \multirow[t]{2}{*}{ Fine sand } & \multirow[t]{2}{*}{1980} & $\mathrm{CM}$ & 5.0 & 0.109 & & \\
\hline & & CS & 1.6 & 0.029 & 10.0 & 0.143 \\
\hline \multirow[t]{2}{*}{ Loamy fine sand $\mathrm{H}$} & \multirow[t]{2}{*}{1981} & $\mathrm{CM}$ & 5.0 & 0.082 & . & . \\
\hline & & CS & 1.6 & 0.008 & 16.0 & 0.136 \\
\hline \multirow[t]{2}{*}{ Loamy fine sand $\mathrm{L}$} & \multirow[t]{2}{*}{1981} & $\mathrm{CM}$ & 3.0 & 0.088 & & \\
\hline & & CS & 0.9 & 0.000 & 5.0 & 0.146 \\
\hline \multirow[t]{2}{*}{ Fine sand } & \multirow[t]{2}{*}{1982} & $\mathrm{CM}$ & 10.0 & 0.111 & & \\
\hline & & $\mathrm{CS}$ & 2.5 & 0.053 & $>160.0$ & 0.217 \\
\hline \multirow[t]{3}{*}{ Fine sandy loam } & \multirow[t]{3}{*}{1982} & CL & 160.0 & 0.135 & & \\
\hline & & $\mathrm{CM}$ & 1.6 & 0.028 & 30.0 & 0.114 \\
\hline & & CS & 1.3 & 0.015 & 5.0 & 0.073 \\
\hline
\end{tabular}


sistance which causes a decrease in root growth rate of $50 \%$ may be assumed. In a rather homogeneous soil structure this corresponds with a penetration resistance of about 1.5 MPa for maize (Boone \& Veen, 1982).

With the penetration resistances measured at various soil water contents and the appropriate water retentivity curves, for treatments CM and CS the soil water content and soil water potential at both critical penetration resistances was estimated (Table 8).

A penetration resistance of $1.5 \mathrm{MPa}$ is reached in treatment CS at a matric water potential at or slightly lower than field capacity. In treatment CM soil water content and potential should decrease clearly whereas in treatment CL this value, except for the fine sandy loam, is not reached. A value of $3 \mathrm{MPa}$ is already obtained at $h_{\mathrm{m}}=$ $-5 \mathrm{~m}$ in treatment CS of the fine sandy loam and the loamy fine sand with the smallest porosity. Matric water potentials are smaller in the less compacted loamy fine sand and in fine sand, especially after grass. The smaller the difference between field capacity and the water content and potential at which a penetration resistance of $3 \mathrm{MPa}$ is reached, the higher the risks a suboptimal crop water supply. It may be concluded that in the fine sandy loam and the loamy fine sand with a small porosity a risky situation may develop easily whereas in the fine sand previously in grass this will happen only in extreme cases.

\section{Potentials and restrictions of soil structures for root growth in relation to matric water potential}

The combination of the aspects discussed in the previous sections enables the estimation of potential root growth as affected by soil compaction and matric water potential. The following assumptions are made.

1. Soil aeration is fully inhibitive for root growth at the LCAL and non-restrictive at the UCAL for oxygen diffusion. The actual oxygen consumption by the soil serves as a minimum.

2. Mechanical impedance is fully inhibitive for root growth at the UCML and partly restrictive at the LCML in soils with a homogeneous structure. In heterogeneous soil structures limits should be increased.

3. The more the matric water potential at which soil aeration becomes insufficient is above field capacity $\left(h_{\mathrm{m}} \approx-1 \mathrm{~m}\right)$ and the closer the matric water potential at which mechanical impedance strongly restricts root growth is to the permanent wilting point $\left(h_{\mathrm{m}} \approx-160 \mathrm{~m}\right)$ the higher the potential for root growth is.

Moderate compaction of the fine sand is not or weakly restrictive unless the soil is excessive wet or dry (Fig. 3). Severe compaction is weak to moderate restrictive: a soil water potential a little above $h_{\mathrm{m}}=-0.9 \mathrm{~m}$ or below $h_{\mathrm{m}}=-10 \mathrm{~m}$ are potential ris$\mathrm{ky}$. The mechanical restriction may be overestimated because some large pores are present. Potential risks are smaller when grass instead of maize is a previous crop, unless the oxygen consumption remains as high as measured at crop emergence.

Moderate compaction of the loamy fine sand at a matric water potential of $h_{\mathrm{m}}=$ $-1 \mathrm{~m}$ is not or weakly restrictive, but at $h_{\mathrm{m}}=-0.9 \mathrm{~m}$ clearly restrictive. In this last case aeration may be sub-optimal at field capacity. Mechanical restrictions are less clear. Severe compaction, especially at a matric water potential above $-0.9 \mathrm{~m}$ is po- 


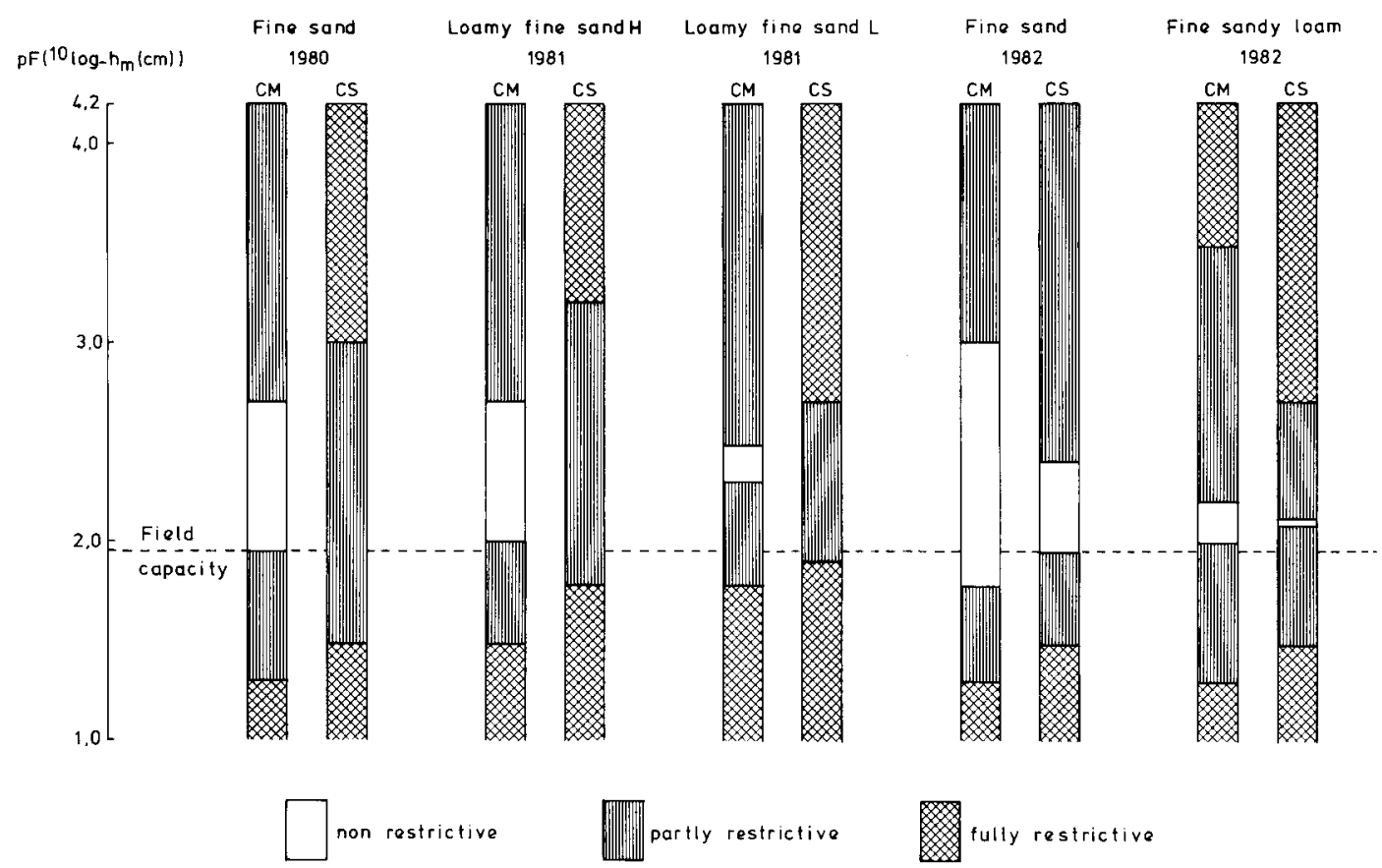

Fig. 3. Range of non-restrictive and restrictive matric water potentials of treatments $\mathrm{CM}$ and CS based on gas diffusion coefficients and penetration resistances.

tentially dangerous: the range of matric water potentials without some restriction is very small or absent. Pore size distribution is unfavourable.

Moderate compaction of the fine sandy loam is weakly, severe compaction moderately restrictive when matric water potential is clearly above field capacity or smaller than $h_{\mathrm{m}}=-5 \mathrm{~m}$. A clay content of $10 \%$ indicates some capacity for shrinkage upon drying and therefore mechanical restriction will be not absolute.

\section{Discussion}

There is a growing demand for knowledge about the range of optimal soil structure for specific conditions and crops. The technical possibilities for the realisation of specific soil structures during crop growth are increasing. New tillage systems such as wide, permanent bed systems create a number of options. The second reason for this growing demand is opposite to the first: optimalization of present farming systems imposes technical limitations to part of the system. The enormous extension of spreading liquid livestock manure minimized and delayed the time available for soil tillage and therefore necessitates some degree of artificial compaction before sowing maize. However, the heavy equipment used for spreading the manure substantially increases the risks of compaction of the soil below the usual ploughing depth.

In developing criteria for soil structure an analytical approach, by studying spe- 
cific aspects, or an integral approach by pure empirical field research may be followed. Both approaches have their own limitations. In this study a combination of both procedures is proposed.

When the range of optimal soil structure is represented by a series of soil porosities, limitations arise at the dense as well as at the loose side of this range. To reduce the complexity, emphasis is laid on the dense part of the range. In a dense soil, root growth and activity may be limited in (very) wet and (very) dry soil conditions: by soil aeration and mechanical impedance, respectively.

Although soil aeration acts also indirectly by biochemical factors (e.g. (de)nitrification), attention is concentrated to the availability of oxygen in gas-filled pores at different depths in the soil. This macrotransport is the boundary condition for the microtransport from the nearest gas-filled pore through the solid particle-air-water complex to the root surface. The smaller the area of the root surface in direct contact with the continuous system of gas-filled pores is, the higher the oxygen concentration in these pores should be (de Willigen \& van Noordwijk, 1984; van Noordwijk \& de Willigen, 1984). This aspect is included arbitrarily in the earlier defined lower and upper critical limits of the oxygen diffusion coefficient $D\left(\mathrm{O}_{2}\right)$ by limiting oxygen concentrations of 1 and $10 \%$, respectively. More realistic limits will be known if data become available on root-soil contact in relation to soil structure.

For the various sandy soils distinct differences are observed in the oxygen diffusion-volume fraction of gas $\left(D\left(\mathrm{O}_{2}\right)-\phi_{\mathrm{g}}\right)$ relationship. The relationship for the fine sand is similar to the relationship for single grain structures (Bakker et al., 1986). When this soil was in grass the relationship is more favourable and resembles a fairly well structured soil. Obviously the grass root system provided continuous gas-filled pores for diffusion. A similar result is obtained for the fine sandy loam but the loamy fine sand scored less. Because no distinct influence of total pore space on the $D\left(\mathrm{O}_{2}\right)-\phi_{\mathrm{g}}$ relationship is obtained the effect of compaction is the reduction in $\phi_{\mathrm{g}}$ present at any matric water potential. This simplifies the establishment of predictive aeration indices for sandy soils. The prediction however, is complicated by a reliable calculation of the oxygen consumption. Because the consumption by the soil and the root system of a growing crop are of a similar magnitude (Brown \& Fountaine, 1965), the consumption by the soil is an absolute minimum. The dynamic properties of the processes indicate that only measurements under strictly standardized conditions (e.g. soil water and temperature) of large undisturbed soil samples taken at the proper time will give valuable results which can be compared. Soil oxygen concentrations obtained around crop emergence may provide empirical information at the start of the growing season. These figures will gain when information is available about soil temperature, amount, distribution, turnover rate and date of application of freshly applied organic substances and applied soil tillage. Amendments with a high turnover rate have a large flux during a rather limited time (Bakker, 1982). The same is known for soil loosening by tillage (Brown \& Fountaine, 1965). In the present experiments the consumption appears to be increased by soil compaction so it may be concluded that every mechanical disturbance of the soil has an impact on the consumption of oxygen.

When soil water content decreases the soil matrix becomes more rigid and there- 
fore the mechanical aspect of root growth gains importance in compacted soils. By compaction the force needed to widen pores increases and the number of pores with a diameter equal or larger than the growing root tips decreases. For the first aspect penetration resistances are indicative. As a lower critical limit of mechanical impedance (LCML), the soil conditions which cause a decrease in root growth rate of $50 \%$ may be assumed. In a rather homogeneous soil structure this corresponds with a penetration resistance of about 1.5 MPa for maize (Boone \& Veen, 1982). As an upper critical limit (UCML) soil conditions may be considered which allow a root growth which is only a fraction of the growth without mechanical impedance or completely stops root growth. A value of $3 \mathrm{MPa}$ is appropriate in a homogeneous soil structure without pores equal or larger than the growing root tips (e.g. Taylor \& Gardner, 1963). This limit has to be regarded as a safe limit. In less homogeneous soils the mean critical value will be higher because mean values obscure the rootability of the weaker spots (Groenevelt, 1984). This points to the real problem: how to quantify the number and continuity of macropores with dimensions which accommodate roots. For maize roots with a mean diameter of main root axes of 1000 $\mu \mathrm{m}$ requirements are higher than, for instance, for ryegrass with root diameters of 100-200 $\mu \mathrm{m}$ (Boone, 1976).

Present methods characterizing the system of large pores are not well suited to evaluate the mechanical aspect of soil rootability. Most limitations are related to the pore size range or pore geometry. The highest matric water potential applicable is $h_{\mathrm{m}}=-0.1 \mathrm{~m}$ and represents all pores with a diameter $>300 \mu \mathrm{m}$. Only thin sections, which are not (yet) adapted for routine purposes, may provide more essential information about the system of these large pores. Measurements of air and saturated water permeability provide information about pathways which are not necessarily similar to the paths taken by growing roots. A method specially designed to simulate root growth in beds of aggregates in dependance of mechanical forces was proposed by Dexter (1976). For (very) compact soils with a limited number of large pores the analysis of thin sections is still required. The determination at a high matric water potential of the ratio between the intrinsic air permeability and the relative oxygen diffusion coefficient may provide some additional information. If it is assumed that all gas-filled pores have a diameter of the main root axes it is possible to calculate the maximum number of these pores. This may aggrevate the $3 \mathrm{MPa}$ mechanical impedance boundary or relieve it to a higher limiting value. A similar indication may be derived from the potential shrinkage and swelling characteristics of a soil. In untilled loess soil with large biopores (Ehlers, 1982) and in untilled marine loam soil (Boone et al., 1984) root growth of cereals was observed until penetration resistances reached a value of 5 and $4 \mathrm{MPa}$, respectively.

Soil structures which guarantee a maximum crop yield under a wide range of environmental circumstances are preferable above those with a small range, unless the environment can be controlled adequately. In the proposed concept root growth which allows optimal crop growth is supposed to be possible between the critical limits of soil aeration and mechanical impedance and therefore have been related to the matric water potentials. The lower the matric water potential at which aeration becomes sufficient the greater the chance of a hampered root 
growth in wet conditions. Especially situations with a sufficient aeration only at matric water potentials lower than field capacity are potentially limiting. The lower the matric water potential at which root growth is unimpede the smaller the risk of insufficient root growth in dry situations. In the Netherlands in years with a dry period after sowing, matric water potential at the rooting front in the arable layer is generally $h_{\mathrm{m}}=-2$ to $-5 \mathrm{~m}$, the last figure therefore may be taken as a minimum value. The narrower the range of matric water potentials without both limitations the greater the risks. When root growth is limited even at the best possible situation a real dangerous situation is to be expected. This situation occurs in the lower part (L) of treatment CS on loamy fine sand.

\section{Conclusions}

1. Soil porosities obtained by compaction of sandy soils were affected by soil composition, soil conditions and cropping history. A slightly wetter soil gave a smaller and three-year grass instead of maize as a previous crop, a larger porosity.

2. For the fine sand the relationship between the oxygen diffusion coefficient and the volume fraction of gas was similar to the relation for a single grain structure. A more favourable relationship was found when grass instead of maize had been the previous crop or when a significant amount of clay was present in the soil. The porosity did not have a specific influence on the relationship. The primary effect of compaction on oxygen diffusion therefore is the reduction in the volume fraction of gas.

3. Soil compaction shortly before sowing markedly increased the oxygen consumption of the soil at emergence.

4. The combination of several aspects of soil aeration and mechanical impedance in relation to matric water potential enables the evaluation of soil structure in relation to root growth.

5. The narrower the range of matric water potential which allow an unimpeded root growth, the greater the potential risks for plant growth and the greater the need for a controlled supply of water. Soil structures which substantially impede root growth even at the most favourable matric water potential are to be classified as dangerous. This situation was encountered in the lower part of the experiment on loamy fine sand severely compacted at field capacity.

\section{References}

Bakker, H. de \& J. Schelling, 1966. System of soil classification for the Netherlands. The higher levels. Pudoc, Wageningen, 217 pp. (Dutch, English summary).

Bakker, J. W. \& A. P. Hidding, 1970. The influence of soil structure and air content on gas diffusion in soils. Netherlands Journal of Agricultural Science 18: 37-48.

Bakker, J. W., 1982. In: Annual report, Institute for Land and Water Management Research (ICW): $62-63$

Bakker, J. W., F. R. Boone \& P. Boekel, 1986. The influence of soil structure on the gas diffusion coefficient of several soils in the Netherlands. Report, Institute for Land and Water Management Research (ICW) (in press). 
Boone, F. R., 1976. Soil tillage as a growth regulator. Landbouwkundig Tijdschrift (88)6: 167-172.

Boone, F. R., S. Slager, R. Miedema \& R. Eleveld, 1976. Some influences of zero-tillage on the structure and stability of a fine-textured river levee soil. Netherlands Journal of Agricultural Science 24: 105-119.

Boone, F. R. \& B. W. Veen, 1982. The influence of mechanical resistance and phosphate supply on morphology and function of maize roots. Netherlands Journal of Agricultural Science, 30: 179-192.

Boone, F. R., B. Kroesbergen \& A. Boers, 1984. Soil conditions and growth of spring barley on a tilled and untilled marine loam soil. In: Experiences with three tillage systems on a marine loam soil. II: 1976-1979, Chapter 8, p. 124-166. Agricultural Research Reports 925. Pudoc, Wageningen.

Boone, F. R., L. A. H. de Smet \& C. D. van Loon, 1985. The effect of a ploughpan in marine loam soils on potato growth. 1. Physical properties and rooting patterns. Potato Research 28: 295-314.

Brown, N. J., E. R. Fountaine \& M. R. Holden, 1965. The oxygen requirement of crop roots and soils under near field conditions. Journal of Agricultural Science, 64: 195-203.

Dexter, A. R., 1976. Internal structure of tilled soil. Journal of Soil Science 27: 267-278.

Ehlers, W., U. Köpke, F. Hesse \& W. Böhm, 1983. Penetration resistance and root growth of oats in tilled and untilled loess soil. Soil and Tillage Research 3(3): 261-276.

Groenevelt P. H., B. D. Kay \& C. D. Grant, 1984. Physical assessment of a soil with respect to rooting potential. Geoderma 34: 101-114.

Kmoch, H. G., 1961. Die Bestimmung der Luftdurchlässigkeit des Bodens und ihre Bedeutung für einige ackerbauliche Probleme. Gebr. Borntraeger, Berlin, $86 \mathrm{pp}$.

Noordwijk, M. van \& P. de Willigen, 1984. Mathematical models on diffusion of oxygen to and within plant roots, with special emphasis on effects of soil-root contact. 2. Applications. Plant and Soil 77: 233-241.

Soesbergen, G. A. van \& Th. C. Vos, 1971. A penetrometer to be applied in soil survey. Interne mededelingen No 4, Soil Survey Institute, Wageningen, $10 \mathrm{pp}$.

Taylor, H. M. \& H. R. Gardner, 1963. Penetration of cotton seedling taproots as influenced by bulk density, moisture content and strength of soil. Soil Science 96 (3): 153-163.

Willigen, P. de \& M. van Noordwijk, 1984. Mathematical models on diffusion of oxygen to and within plant roots, with special emphasis on effects of soil-root contact. 1. Derivation of the models. Plant and Soil 77: 215-231. 